\title{
Waste Fibre Reinforced Ecocomposites
}

\author{
A. Lundahl ${ }^{1, a}$, R. Fangueiro ${ }^{2, b}$, F. Soutinho ${ }^{2, c}$, F. Duarte $^{3, d}$ \\ ${ }^{1}$ The Swedish School of Textiles, University of Boras, 50190 Borås, Sweden \\ ${ }^{2}$ Center for Textile Science and Technology, University of Minho, Campus de Azurém \\ 4800-058 Guimarães, Portugal \\ ${ }^{3}$ Department of Polymer Engineering, University of Minho, Campus de Azurém \\ 4800-058 Guimarães, Portugal \\ aanna.lundahl@teknologisk.dk, ${ }^{\mathrm{b}}$ rfang@det.uminho.pt, ${ }^{c}$ filipesoutinho@det.uminho.pt, ${ }^{d}$ \\ fduarte@dep.uminho.pt
}

Keywords: Waste fibre, Ecocomposites, Compression moulding.

\begin{abstract}
With a significant production of waste fibrous material, textile companies are now looking for applications where waste materials could be an added-value material. One viable application of these waste materials is in the combination with polymeric matrices, producing composite materials with interesting properties for specific applications, from furniture to thermal and acoustic insulations. The aim of this work was to study the physical and mechanical properties of waste fibre reinforced composites and the influence of different parameters on their mechanical behaviour. Results show that a wide range of different properties and performances may be designed by altering various production parameters, such as thickness of the nonwovens used, time and temperature of the compression moulding, relationship between fibre/matrix ratio, polymeric film used and number of layers.
\end{abstract}

\section{Introduction}

Due to environmental concerns, a very large number of companies are currently developing manufacturing processes using alternative materials for their products and seeking new markets. With a significant production of waste fibrous material, different companies are now looking for applications where waste materials may represent an added-value material [1].

One viable application of these waste materials is in the combination with polymeric matrices, producing composite materials with interesting properties for specific applications, from furniture to thermal and acoustic insulations. Once most of these waste fibrous materials are based on natural fibres, the production of eco-composites can be a reality, especially when environmental friendly matrices are used, such as recyclable polymeric materials.

Composites reinforced by fibres are increasingly being considered for several uses when high performance is required [2]. The light weight, potentially high overall durability, tailor ability and high performance attributes enable the use of composite materials in areas in which the use of conventional material might be constrained due to durability, weight or lack of design flexibility.

However, the definition of high performance material is not only related to materials that present high mechanical behaviour, but also to materials presenting any other high specific behaviour [3] Therefore, any kind of material with high durability, extreme light weight or corrosion resistance higher than the conventional materials, for example, can be considered as a high performance material. Roof and wall panels, automobile interiors, storage devices, thermal and acoustic insulation material, furniture, and others, are few examples of applications where materials with specific high behaviour are required and the mechanical behaviour is not the most important property.

Within this study waste fibres are collected and transformed into a fibrous mat of more homogenously mixed and combed fibres, mainly containing natural fibres. The fibre material is processed into a nonwoven fabric. Further, nonwoven samples are combined with thermoplastic 
film of $100 \%$ polypropylene, and prepared as sandwich structures, where several layers of each material are joined into a composite material. Different numbers of layers of both materials are combined in order to achieve several different composite materials with a variation in ratio of polypropylene and the reinforcing nonwoven. Compression moulding technique was used to prepare composite panels, to be evaluated in terms of their mechanical properties.

From the result analysis it is shown that a range of different properties and performance may be produced when altering various production parameters, such as thickness of the nonwovens used, time and temperature of the compression moulding, relationship between fibre/matrix ratio, polymeric film used and number of layers in the composite panel.

\section{Materials and Experimental Work}

Raw Materials. The waste fibre material consisted of about $85 \%$ of cellulosic fibres. This collected textile waste fibrous material was used for the production of nonwoven fabrics.

Nonwoven Materials. Waste fibre reinforcement material was prepared into nonwoven fabric using needle punching technique. Three different nonwoven qualities have been produced with thicknesses of 3,4 and $5 \mathrm{~mm}$. For higher material stability the material is needled through the machine twice, both on right and reverse side. Nonwovens thus obtained present not only different thickness but also different mass/unit area. Nonwoven with $3 \mathrm{~mm}$ of thickness, named Th3, presents $190 \mathrm{~g} / \mathrm{m}^{2}$, Th4, nonwoven with $4 \mathrm{~mm}$ presents $260 \mathrm{~g} / \mathrm{m}^{2}$ and $T h 5$, nonwoven with $5 \mathrm{~mm}$ presents $440 \mathrm{~g} / \mathrm{m}^{2}$.

Polypropylene Film. The material to be used as matrix for the composite production is a polypropylene film. The homogeneous polypropylene thin film presents a thickness of $50 \times 10^{-6} \mathrm{~mm}$. The PP- film is co-extruded and is plain and untreated on both sides.

Ecocomposites. Composite materials have been produced using compression moulding technique. Nonwovens and PP-film have been prepared in sandwich style. The structure is placed in a compression frame. A film of non-stick Teflon sheet, PTFE, is covering both the top and the bottom of the sandwich structure, in order to prevent the PP thermoplastic material to stick to the frame when melted. All composite samples produced are of the same width and length, 200x200 mm. The thickness depends on the compression frame used in the compression mould - $2 \mathrm{~mm}$ and $5 \mathrm{~mm}$ frames were used. Panels were compressed at $175^{\circ} \mathrm{C}$, under a total load of 20 tonnes.

Experimental Plan. In the production of composite panels, a number of parameters were varied in order to understand their influence on the mechanical properties of the composite materials obtained. These parameters were as follows:

i) ratio of reinforcement and thermoplastic material by varying the number of layers of nonwoven according to the number of polypropylene film. Three percentage ratios of thermoplastic polypropylene and waste fibre reinforcing nonwoven materials were used. The production parameters for composite panels are based on variations of the amount of thermoplastic film layers and the amount of nonwoven layers.

ii) number of nonwoven layers used for composite production is determined in the preparation of the sandwich structure: 1, 2, 3 and 4 layers of nonwoven;

iii) nonwoven fabrics used for the composite panel- three different nonwoven fabrics were used as reinforcement material, with original thickness of 3,4 and $5 \mathrm{~mm}$;

Figure 1 illustrates the plan of composite material samples produced with the compression frame of $2 \mathrm{~mm}$ in thickness. 


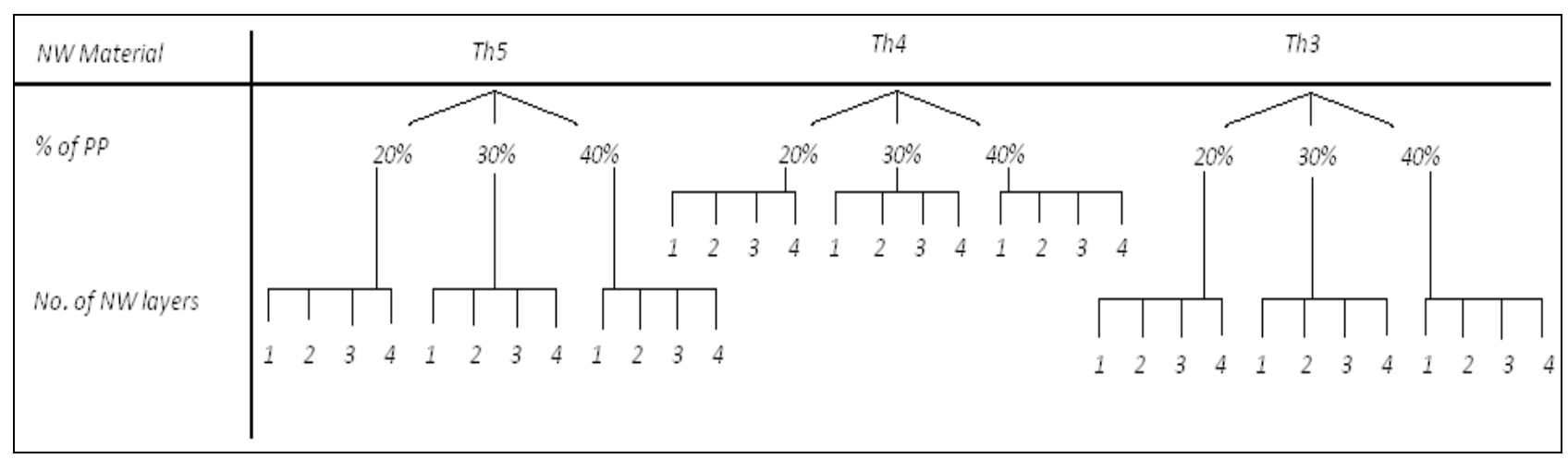

Fig. 1 - Illustrations of the plan of composite materials samples produced

Figure 2 shows some of the composite panels obtained using both compression frames, 2 and $5 \mathrm{~mm}$.

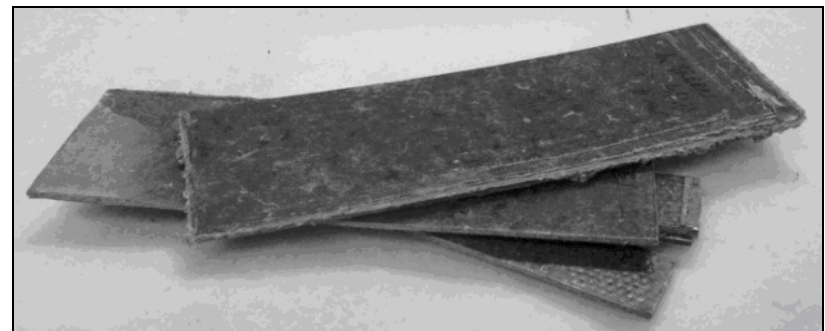

a)

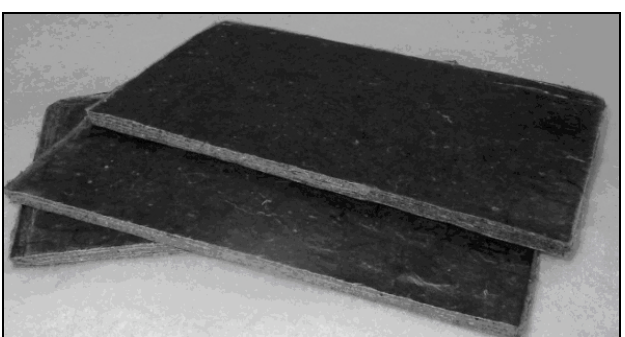

b)

Fig. 2 - Composite panels produced with compression frame of a) $2 \mathrm{~mm}$ and b) $5 \mathrm{~mm}$ thickness

\section{Test Methods}

Nonwoven Mechanical Properties. The mechanical properties of the nonwoven fabrics were evaluated according to International Standard ISO 9073-3: 1989. All specimens were tested in the machine direction and accordingly all layers of nonwoven were placed in the same direction when prepared the sandwich structure.

Polypropylene Film. The mechanical properties of the PP film were evaluated according to Standard ASTM International D822 -02.

Ecocomposites. The composite panels produced from waste fibrous material and polypropylene films were tested using an Universal Tensile Machine, Hounsfield H100 KS, in order to evaluate their mechanical properties, including: tensile and bending. For tensile, all tests are made in series of five per composite material. Samples of $25 \times 200 \mathrm{~mm}$ were used. The gauge length is $50+-1 \mathrm{~mm}$ and initial length between clamps $150 \mathrm{~mm}$ for $2 \mathrm{~mm} / \mathrm{min}$ of crosshead speed.

\section{Results and Discussion}

Nonwoven Mechanical Properties. The tensile properties of the non-woven materials in terms of tensile strength and elongation for each single nonwoven fabric, are presented in Table1. Analysing this Table 1, it is possible to conclude that tensile strength is decreasing with the thickness decreasing which will influence the properties of the composite materials produced. 
Table 1 - Nonwoven mechanical properties

\begin{tabular}{ccccccc}
\hline \multirow{2}{*}{$\begin{array}{c}\text { Nonwoven } \\
\text { fabric }\end{array}$} & \multicolumn{3}{c}{ Max Force } & \multicolumn{3}{c}{ Extension } \\
\cline { 2 - 7 } & Average [N] & SD [N] & CV [\%] & Average [\%] & SD [\%] & CV [\%] \\
\hline Th5 & 37.09 & 10 & 2 & 40.15 & 10 & 25 \\
Th4 & 6.70 & 2 & 36 & 45.11 & 5 & 11 \\
Th3 & 1.41 & 0.2 & 12 & 15.73 & 4 & 25 \\
\hline
\end{tabular}

Polypropylene Film. Physical and mechanical properties of the polypropylene film used are shown in Table 2.

Table 2 - Physical and mechanical properties of polypropylene film

\begin{tabular}{ccccc}
\hline $\begin{array}{c}\text { Thickness } \\
{[\text { microns }]}\end{array}$ & $\begin{array}{c}\text { Density } \\
{\left[\mathrm{g} / \mathrm{cm}^{3}\right]}\end{array}$ & $\begin{array}{c}\text { Shrinkage }[\%] \\
\left(120^{\circ} \mathrm{C}, 5 \mathrm{~min}\right)\end{array}$ & $\begin{array}{c}\text { Max Force } \\
{[\mathrm{N}]}\end{array}$ & $\begin{array}{c}\text { Extension } \\
{[\%]}\end{array}$ \\
\hline $50( \pm 3)$ & 0,905 & $1-4$ & 10,35 & 542 \\
\hline
\end{tabular}

Comparative Analysis. The stress at break-extension curves as results of tensile tests of nonwoven fabrics (Th3 2 layers), the PP plastic film and the composite material produced with both materials (Th3 2 layers 20\%PP) is presented in Fig. 3.

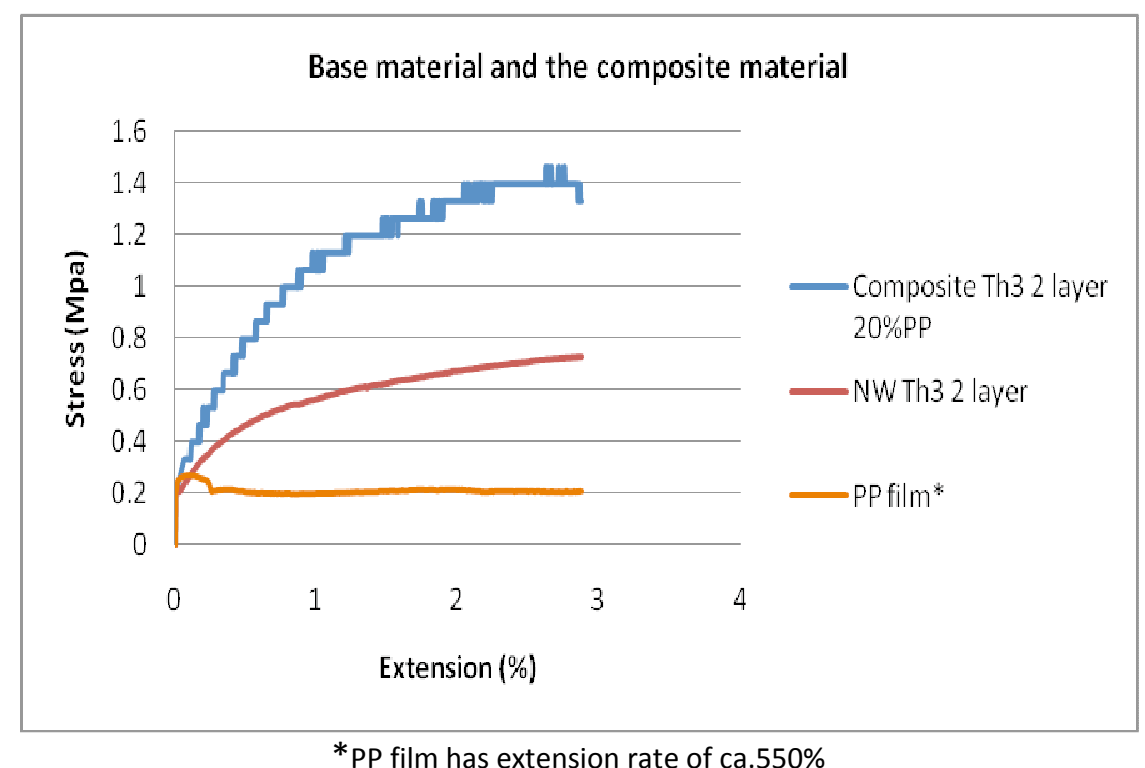

Fig. 3 - Stress-extension typical curves from tensile tests for nonwoven, PP film and produced composite material

As can be seen, the combination of PP with nonwoven improves significantly the mechanical response as the composite material presents better mechanical behaviour than that of the components.

\section{Ecocomposites.}

Influence of the Amount of Polypropylene. Fig. 4 shows the influence of the polypropylene amount on the mechanical performance of the composite materials produced. 


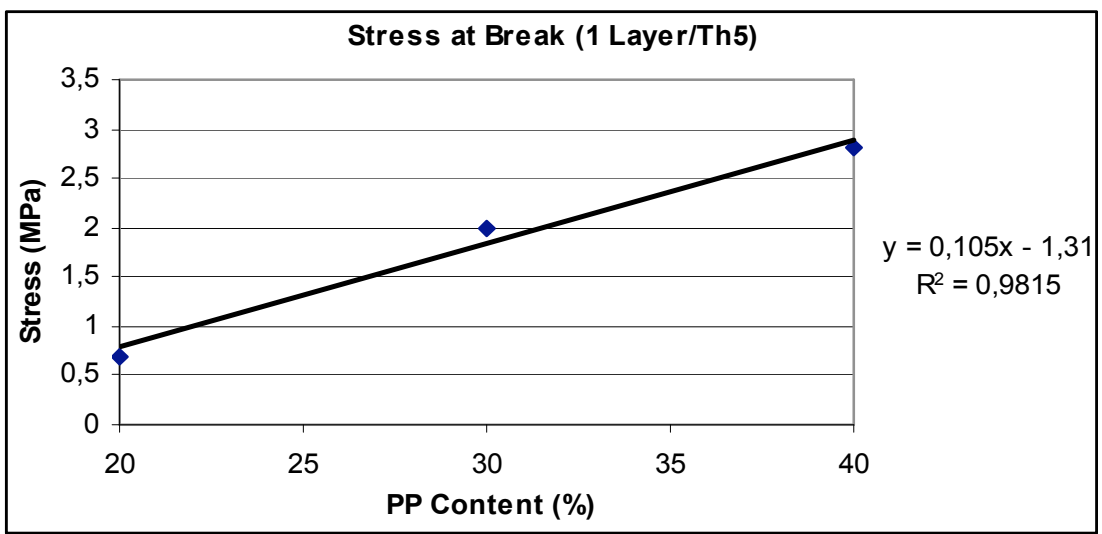

Fig. 4 - Typical stress trend with increased PP content

As can be seen there is a linear correlation between the amount of PP and the stress at break of the correspondent composite material. The more is the plastic used in the composite panel, the higher is the load that it can bear.

Influence of Nonwoven Thickness. Fig. 5 shows the influence of the nonwoven thickness on the mechanical performance of the composite materials produced. The higher is the thickness of the nonwoven used the higher is the mechanical performance of the correspondent composite material, This behaviour may be explained by the variation of the amount of fibers provided by nonwovens with different thickness, i.e., the higher is the thickness the higher is the nonwoven density.

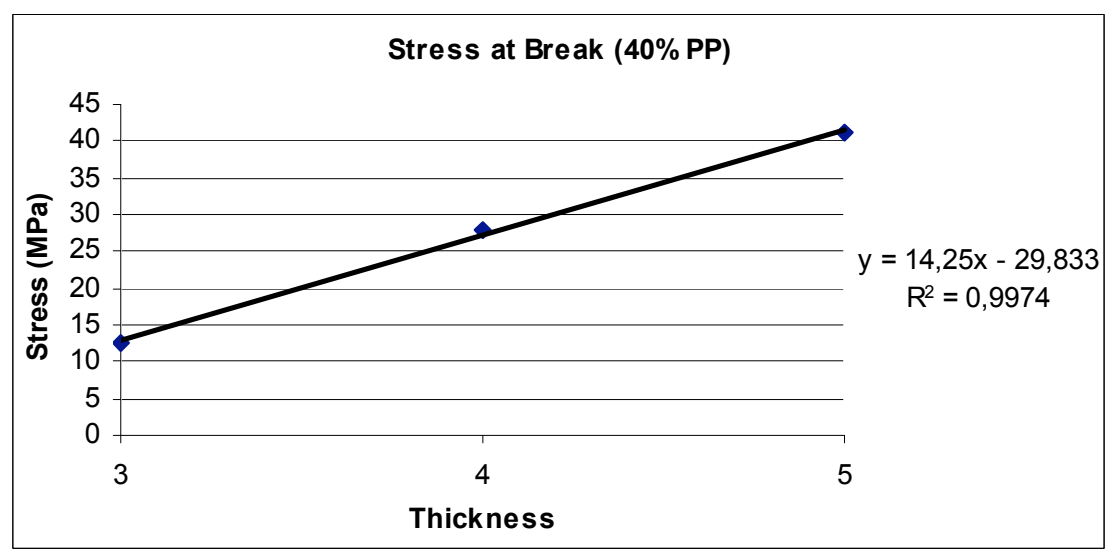

Fig. 5 - Typical stress trend with increase of nonwoven fabric thickness

Influence of the Number of Layers. Fig. 6 shows the influence of the nonwoven thickness on the mechanical performance of the composite materials produced, for the same thickness and amount of PP.

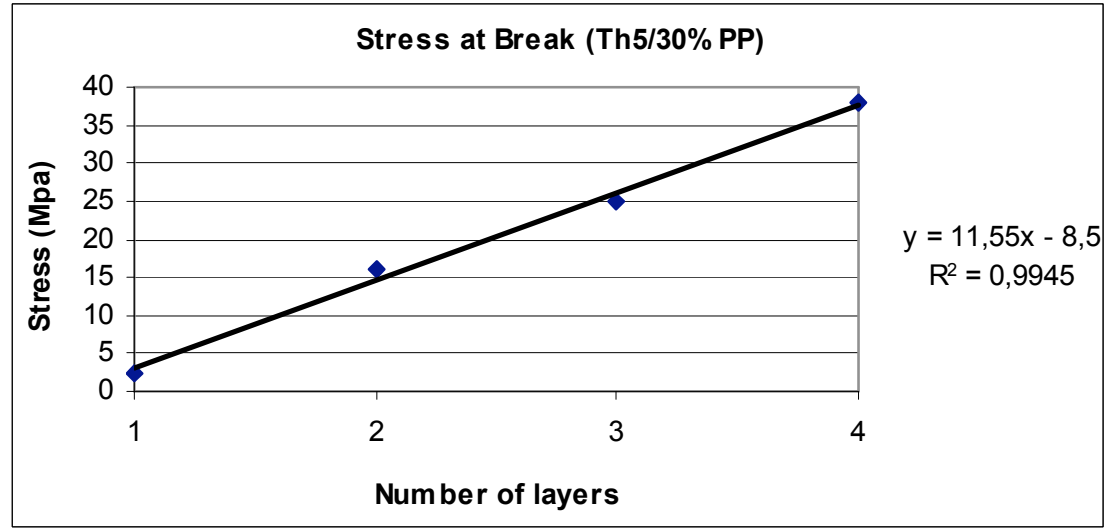

Fig. 6 - Typical stress trend with increase of number of layers 
Analyzing the results obtained, one can see that the numbers of nonwoven layers used are influencing directly the mechanical behaviour of the composites in a linear way. The higher is the number of layers the better is the mechanical performance due to the increase on the volume fraction of reinforcing material, i.e., nonwoven.

\section{Conclusions}

This study on waste fibre reinforced ecocomposites presents a large interest for a sustainable development of a waste fibre reinforced composites and their potential application areas. Several possible applications may be a reality in the near future, where the composite panel's properties are suitable and the eco-issues are of paramount importance.

Results obtained show that composite panels with a large variety of properties can be produced by varying their production parameters. Correlations between the parameters nonwoven thickness, nonwoven number of layers and amount of polypropylene and the mechanical performance of the ecocomposites obtained were established. The relationship between these parameters enables to design the most suitable material for a particular application with very specific requirements. The correlation between the parameters studied and the mechanical properties are of some type, i.e., the higher is the parameter value the higher is the mechanical response of the composite material.

\section{References}

[1] A.C. Wooldridge: Life Cycle Assessment for Re-use/Recycling of Donated Waste Textiles, Compared to Use of Virgin Material: A UK Energy Saving Perspective, Resources, Conservation and Recycling, Vol. 46 (2006), p.94-103

[2] M.F.S.F. de Moura, A.B. de Morais and A.G. Magalhães: Materiais Compósitos - Materiais, Fabrico e Comportamento Mecânico, Publindústria, Porto (2006), p.15-21.

[3] M. G. Gomes, R. Fangueiro, G. Jobim and C. Gonilho Pereira, Composite Materials Reinforced by Waste Fibers, Mechanics \& Materials in Design $-5^{\text {th }}$ International Conference, Porto, Portugal 24-26 July, 2006. 